\title{
A simple, fast and inexpensive method for mutation scanning of CFTR gene
}

\author{
Juan Emilio Figueredo Lago 1*, Anny Armas Cayarga', Yaimé Josefina González González \\ and Teresa Collazo Mesa²
}

\begin{abstract}
Background: Mutation scanning methods in Cystic Fibrosis Transmembrane Conductance Regulator (CFTR) gene may not distinguish between a Cystic Fibrosis (CF) causing mutation and a benign variant. We have developed a simple and fast method for scanning 14 selected CF-causing mutations which have high frequency in Latin America.
\end{abstract}

Methods: In a group of 35 samples coming from CF patients previously characterized and using two allele-specific real-time multiplex PCRs targeting wild-type and mutant alleles respectively, we detect the presence of mutations by analyzing the Ct variation. Twenty-five samples without mutations considered non-carrier samples, were also included in this study. High Resolution Melting Analysis (HRMA) was performed to confirm the result of the scanning method and in most cases allowed the genotype determination.

Results: The results validate this method for CF diagnosis. A least one CFTR gene mutation was detected in the samples of CF patients, as predicted by their $\Delta C$ t values. The $\Delta C t$ value also indicated the zygosity of the sample according to the distribution of CFTR gene mutations. In most cases, HRMA allowed the identification of the mutation(s), thereby confirming the efficiency of this scanning strategy.

Conclusions: This strategy simplifies the detection of CF, reducing the analysis of 14 CF-causing mutations to two parallel reactions and making the procedure compatible with the analysis of a large number of samples. As the method is fast, inexpensive and highly reliable, it is advisable for scanning CFTR gene mutations in newborns, patients with a clinical suspicion of CF as well as in the preconception carrier screening.

Keywords: Mutation scanning, CF-causing mutations, Allele-specific multiplex real-time PCR

\section{Background}

Cystic fibrosis (CF) is a life-shortening hereditary disease caused by mutations in the Cystic Fibrosis Transmembrane Conductance Regulator (CFTR) gene [1]. The study of the CFTR gene represents one of the most frequent genetic analyses performed worldwide [2]. In Latin-American countries, CF and associated disorders have remained unknown entities until recently [3, 4]. Cuba, with a large genetic heterogeneity due to the multiethnic origin of its inhabitants, has reported a significant CF incidence: 1 per 9862 newborns [5].

\footnotetext{
* Correspondence: juan.figueredo@cie.cu

${ }^{1}$ Department of Molecular Biology, Immunoassay Center (CIE) Cubanacan,

Playa, Havana, Cuba

Full list of author information is available at the end of the article
}

The implementation of prenatal and preconception carrier screening using genetic analysis could detect and prevent the disease, but the availability of simple and inexpensive technology for detecting mutations on the CFTR gene is a determining factor in the CF diagnosis. Indirect detection methods such as denaturing gradient gel electrophoresis (DGGE) and High Resolution Melting Analysis (HRMA) are techniques designed to explore the gene, exon by exon, for abnormalities [6]. HRMA of PCR products is based on monitoring the fluorescence released during the melting of double-stranded DNA bound to a saturation dye [7]. Regardless their widespread use, these methods performed for CFTR gene scanning may not distinguish between a CF-causing mutation and a benign variant. This uncertainty in scanning the CFTR gene decreases the utility of these methods [8] 
and they are less feasible in areas in which the profile of CFTR mutations have barely been characterized.

The Amplification Refractory Mutation System (ARMS) is one of the most frequently used methods for detecting CFTR mutations [9]. Recent findings suggest the reliability of detecting individual CFTR gene mutations using the real time-ARMS PCR strategy [10, 11]. Through the combination of this last and the HRMA technique, carrier (homozygous, heterozygous) and noncarrier samples can be detected and subsequently differentiated according to their melting profile [12]. By developing a method that includes these advantages and considering frequent mutations that cause CF in Cuba, the National Health System will have a more comprehensive CF screening program and will reduce the time and cost of the analysis of patients.

\section{Methods}

The aim of this work was to develop a cost effective method to scan 14 CF-causing mutations on the CFTR gene using a SYBR Green based real-time multiplex ARMS PCR. HRMA was also used for identifying the mutation(s) according to their amplicon melting profile. The mutations included in this method and with documented frequency in Latin America [13-15] were: R334W, I507del, F508del, 1717-1G > A, G542X, G551D, R553X, $1811+1,6 \mathrm{KbA}>\mathrm{G}, 2183 \mathrm{AA}>\mathrm{G}, 3120+1 \mathrm{G}>\mathrm{A}$, 3272-26A > G, R1162X, W1282X and N1303K.

We performed the mutation scanning in 60 samples, 35 of them from CF patients with a known CFTR genotype that were confirmed by the commercial CF StripAssay 4-410 panel, (ViennaLab Diagnostics, Austria) and DGGE technique. The genotypes of the samples were: $\mathrm{R} 334 \mathrm{~W} /$ wild-type (wt) (2), I507del/wt (2), F508del $/ w t$ (3), G542X/wt (4), R553X/wt (2), $3120+1 \mathrm{G}>\mathrm{A} / w t$ (2), R1162X/wt (2), R334W/F508del (3), I507del/F508del (4), F508del/F508del (5), 1717-1G > A/F508del (1), N1303K/ F508del (1), I507del/2183AA > G (1), G542X/R1162X (1), R334W/R334W (2). Twenty five other non-carrier samples were used for validating this method. Genomic DNA (gDNA) was extracted by the salt precipitation method. The quality and concentration of gDNA was photometrically determined. All samples were kindly provided by the National Center of Medical Genetics (CNGM, Cuba).

We designed allele-specific primers to selectively amplify the wild-type and mutant alleles in parallel reactions. The selection of appropriate primers is an important factor for performing the multiplex PCR in which the specific amplification of a target requires that primers do not have matches to other targets. The same set of primers were used for detecting the mutations I507del and F508del. The simultaneous detection of both mutations allowed to reduce the number of primers in the multiplex PCR. Additionally, the same common primer was employed to detect mutations 1717-1G > A, G542X, G551D and R553X. All analyses were performed in a reaction volume of $23 \mu \mathrm{L}$ in capped tube strips by using the SLAN 96P real-time PCR system (Shanghai Honshi Medical Technology Co., Ltd; China). Each reaction mixture contained 1× Absolute qPCR SYBR Green Mix (Thermo Scientific) and 23 primers flanking 13 targets (Table 1). During the optimization steps, primer concentrations were set to $0.1 \mu \mathrm{M}$, the volume was completed to $20 \mu \mathrm{L}$ with DNase-free water and finally $3 \mu \mathrm{L}$ of template gDNA were added. The thermal PCR profile was: 15 min at $95^{\circ} \mathrm{C}$ for Thermo Start DNA Polymerase activation, followed by 27 amplification cycles $\left(95{ }^{\circ} \mathrm{C}\right.$ for $25 \mathrm{~s}, 59{ }^{\circ} \mathrm{C}$ for $20 \mathrm{~s}$ and $72{ }^{\circ} \mathrm{C}$ for $25 \mathrm{~s}$ ). The $\Delta \mathrm{Ct}$ value of every sample was determined as the modular variation among the allele specific reactions $(\Delta \mathrm{Ct}=\mathrm{Ct} \mathrm{mu}$ tant $-\mathrm{Ct}$ wild-type). Every sample with a $\mathrm{Ct}$ value in the mutant $\mathrm{PCR}$ and $\Delta \mathrm{Ct}<7$ was considered a carrier sample.

The mutant PCR products were melted by increasing the temperature from 70 to $90{ }^{\circ} \mathrm{C}$ at a programmed rate of $0.01{ }^{\circ} \mathrm{C} / \mathrm{s}$. Melting curves were analyzed with the aid of the commercial SLAN 96-P software, version 8.2.2 (Shanghai Honshi Medical Technology Co., Ltd; China).

\section{Results}

In order to test the primer's efficiency and to avoid unspecific amplification, the trio of primers designed for a mutation were tested in two simple PCRs (mutant and wild-type) (Fig. 1). Primers were tested using a noncarrier sample. For performing the multiplex PCR we only choose the trio of primers with a $\Delta \mathrm{Ct}$ greater than 7 cycles. The set of primers selected is shown in Table 1 .

The PCR was set at 27 cycles, the point at which the fluorescence of the non-carrier samples in the mutant PCR increases. After PCR, the threshold was set manually over the level of a non-carrier sample (control) to avoid unspecific amplification. For detecting the presence of mutations in every sample, the mutant curve was compared with the wild-type determining the $\Delta \mathrm{Ct}$ value.

The behavior of carrier and non-carrier samples in the allele specific multiplex-PCR scanning 14 CFTR gene mutations is shown in Figs. 2 and 3 respectively. As shown in Fig. 2, a sample which carries at least one of the 14 selected mutations displays a $\mathrm{Ct}$ value before cycle 26 and the $\Delta \mathrm{Ct}<7$. Non-carrier samples do not display a mutant $\mathrm{Ct}$ value (Fig. 3). The number of affected alleles (zygosity) was also distinguishable. All samples carrying one allele have a $3<\Delta \mathrm{Ct}<$ 7 while samples carrying two alleles in trans have a $\Delta \mathrm{Ct}<3$ (Fig. 2). Particularly, samples with F508del homozygous genotype have $\Delta \mathrm{Ct}<1$. Samples with the 
Table 1 Primer sets used for detecting CFTR gene mutations. The same set of primers was used for detecting mutations I507del and F508del. Primers flank 13 targets and allow the detection of 14 CFTR mutations

\begin{tabular}{|c|c|c|c|}
\hline CFTR Mutation & Sequence $\left(5^{\prime}-3^{\prime}\right)$ & Description & Amplicon length (bp) \\
\hline \multirow[t]{3}{*}{ R334W } & TTTGTTAATGCTCCAAGAGAGTCATACCA & antisense common primer & 140 \\
\hline & CCTATGCACTAATCAAAGGAATCATCCTGC & sense wild type & \\
\hline & CCTATGCACTAATCAAAGGAATCATCCTGT & sense mutant & \\
\hline \multirow[t]{3}{*}{ |507del/F508del } & GGGTAGTGTGAAGGGTTCATATGCATAAT & antisense common primer & 146 \\
\hline & GCCTGGCACCATTAAAGAAAATATCATTG & sense mutant & \\
\hline & GCCTGGCACCATTAAAGAAAATATCATCT & sense wild type & \\
\hline \multirow[t]{3}{*}{$1717-1 G>A$} & TAAAATTTCAGCAATGTTGTITTGACC & sense common primer & 221 \\
\hline & TGTCTITCTCTGCAAACTTGGAGATGTTC & antisense wild type & \\
\hline & TGTCTTTCTCTGCAAACTTGGAGATGTTT & antisense mutant & \\
\hline \multirow[t]{3}{*}{ G542X } & TAAAATTTCAGCAATGTTGTITTTGACC & sense common primer & 257 \\
\hline & ACTCAGTGTGATTCCACCTTCTAC & antisense wild type & \\
\hline & СACTCAGTGTGATTCCACCTTCTCA & antisense mutant & \\
\hline \multirow[t]{3}{*}{ G551D } & TAAAATTTCAGCAATGTTGTTITTGACC & sense common primer & 285 \\
\hline & GCTAAAGAAATTCTTGCTCGTTGCC & antisense wild type & \\
\hline & AGCTAAAGAAATTCTTGCTCGTTGCT & antisense mutant & \\
\hline \multirow[t]{3}{*}{ R553X } & TAAAATTTCAGCAATGTTGTITTGACC & sense common primer & 291 \\
\hline & CACCTTGCTAAAGAAATTCTTGCTAG & antisense wild type & \\
\hline & CACCTTGCTAAAGAAATTCTTGCTAA & antisense mutant & \\
\hline \multirow[t]{3}{*}{$1811+1,6 \mathrm{KbA}>\mathrm{G}$} & TAAATTGGCTTTAAAAATTTCTTAATTG & sense common primer & 135 \\
\hline & CAGGTGTGATTGATAGTAACCTTACTTCT & antisense wild type & \\
\hline & CAGGTGTGATTGATAGTAACCTTACTTCC & antisense mutant & \\
\hline \multirow[t]{3}{*}{$2183 A A>G$} & CAGCCAGACTTTAGCTCAAAACTCATGGG & sense common primer & 170 \\
\hline & AACTCTCCAGTCTGTTTAAAAGATTATT & antisense wild type & \\
\hline & AACTCTCCAGTCTGTTTAAAAGATTAC & antisense mutant & \\
\hline \multirow[t]{3}{*}{$3120+1 G>A$} & ССTCTTACCATATTTGACTTCATCCACG & sense wild type & 197 \\
\hline & ССТСTТАCСАTATTTGACTTCATCCACA & sense mutant & \\
\hline & AATTAACTAAACTTATGTCTATTTTGAAGGC & antisense common primer & \\
\hline \multirow[t]{3}{*}{$3272-26 \mathrm{~A}>\mathrm{G}$} & CATATCTATTCAAAGAATGGCACCAGTGT & sense common primer & 165 \\
\hline & TGCCTGTGAAATATTTCCATAGAAAACGT & antisense wild type & \\
\hline & TGCCTGTGAAATATTTCCATAGAAAACGC & antisense mutant & \\
\hline \multirow[t]{3}{*}{ R1162X } & TाTGCTGTGAGATCTTTGACAGTCATTT & antisense common primer & 200 \\
\hline & TATTITTATTTCAGATGCGATCTGTGAGTC & sense wild type & \\
\hline & TATTITATITCAGATGCGATCTGTGAGTT & sense mutant & \\
\hline \multirow[t]{3}{*}{ W1282X } & CCCATCACTITTACCTTATAGGTGGGCCTC & sense common primer & 178 \\
\hline & CCTGTGGTATCACTCCAAAGGCTTTCCAC & antisense wild type & \\
\hline & CCTGTGGTATCACTCCAAAGGCTTTCCAT & antisense mutant & \\
\hline \multirow[t]{3}{*}{ N1303K } & GAGAGAACTTGATGGTAAGTACATGGGTGTTTC & sense common primer & 206 \\
\hline & GATCACTCCACTGTTCATAGGGATCCAAG & antisense wild type & \\
\hline & GATCACTCCACTGTTCATAGGGATCCAAC & antisense mutant & \\
\hline
\end{tabular}

$\mathrm{Ct}$ of the wild-type curve over cycle 21 and $\Delta \mathrm{Ct}<7$ were not in the appropriate range of concentration. They were retested at higher concentrations $(>50 \mathrm{ng}$ of total DNA).
The HRMA of mutant PCR products confirmed the presence of mutations (Fig. 4). The derivative melting curves indicated the melting temperature of the most amplified target in the multiplex PCR (Fig. 5); this target 


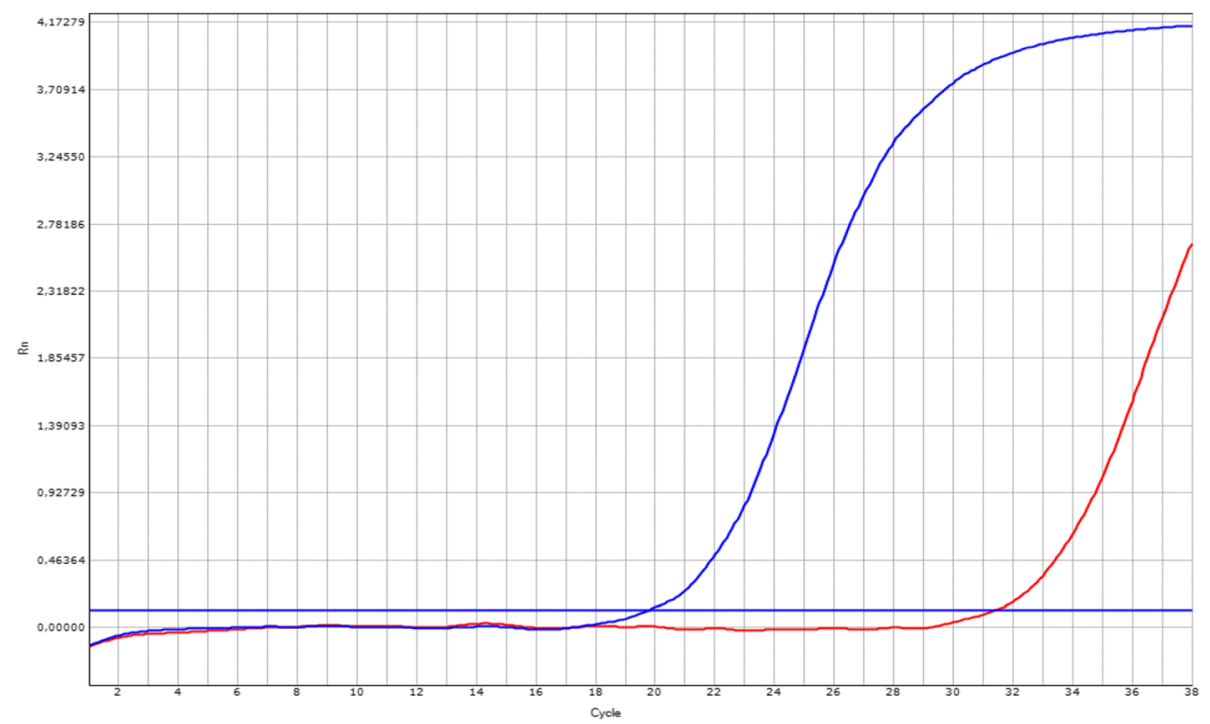

Fig. 1 Allele-specific PCRs evaluating the trio of primers designed for detecting each mutation. Wild type curve (blue) and mutant unspecific amplification (red). All primers were tested using a non-carrier sample

can only be amplified when the mutation is present. A melting temperature profile was obtained for every amplicon. Samples carrying two affected alleles generating amplicons with close temperature profiles could not be correctly resolved using HRMA.

All the CFTR gene mutations were detected in every carrier sample. HRMA efficiently confirmed mutations according to the melting temperature of the amplicon: R334W $\left(81.30{ }^{\circ} \mathrm{C}\right)$, I507del $\left(78.42{ }^{\circ} \mathrm{C}\right)$, F508del $\left(78.21{ }^{\circ} \mathrm{C}\right)$, $1717-1 \mathrm{G}>\mathrm{A}\left(77.14^{\circ} \mathrm{C}\right), \mathrm{G} 542 \mathrm{X}\left(78.08^{\circ} \mathrm{C}\right), \mathrm{R} 553 \mathrm{X}(79.11)$, $2183 \mathrm{AA}>\mathrm{G}\left(78.80^{\circ} \mathrm{C}\right), 3120+1 \mathrm{G}>\mathrm{A}\left(76.26^{\circ} \mathrm{C}\right), \mathrm{R} 1162 \mathrm{X}$ $\left(81.80{ }^{\circ} \mathrm{C}\right)$ and $\mathrm{N} 1303 \mathrm{~K}\left(75.04{ }^{\circ} \mathrm{C}\right)$.

\section{Discussion}

We have developed a simple method for scanning 14 selected CF-causing mutations with high frequency in Latin America. Related studies have been recently reported $[10,11,16]$. We only included the scanning of 14 highly frequently CFTR mutations because of the primers limited availability at the time of this study, but some other mutations could potentially be detected by using this method. By determining the $\Delta \mathrm{Ct}$ value between two allele-specific PCRs, we detected the presence of at least one CFTR mutation in every carrier sample. This method will allow us to confirm

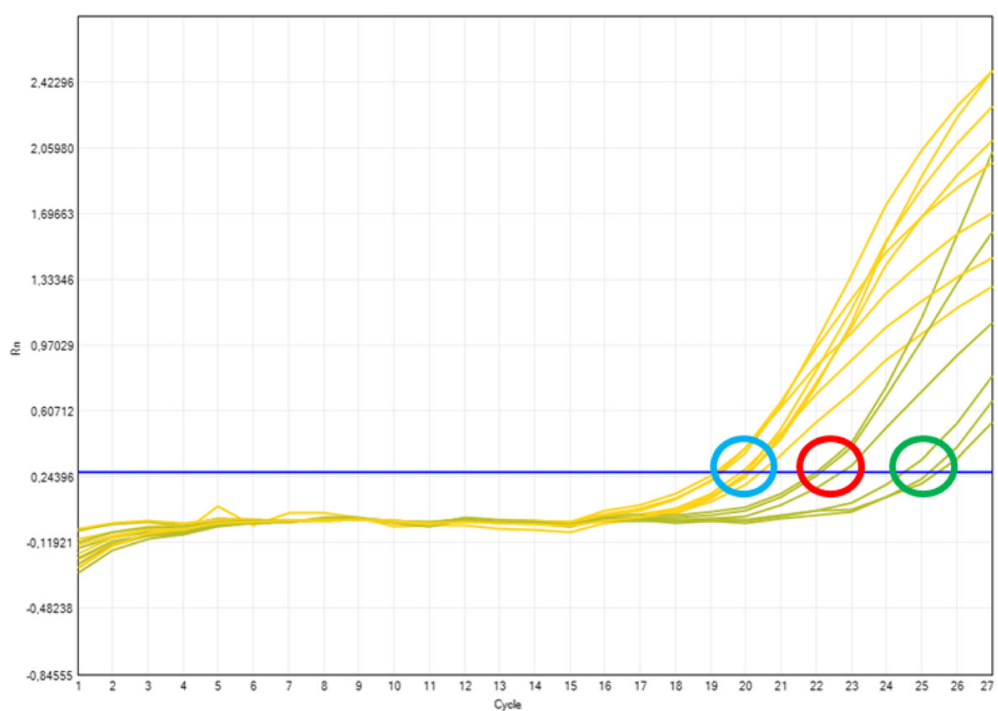

Fig. 2 Behavior of carrier samples in the allele specific multiplex-PCR scanning 14 CFTR gene mutations. Wild type (yellow) and mutant (green) curves of samples carrying one mutation (green circle) or two mutations (red circle). The blue circle points out the Ct zone of the wild type PCR 


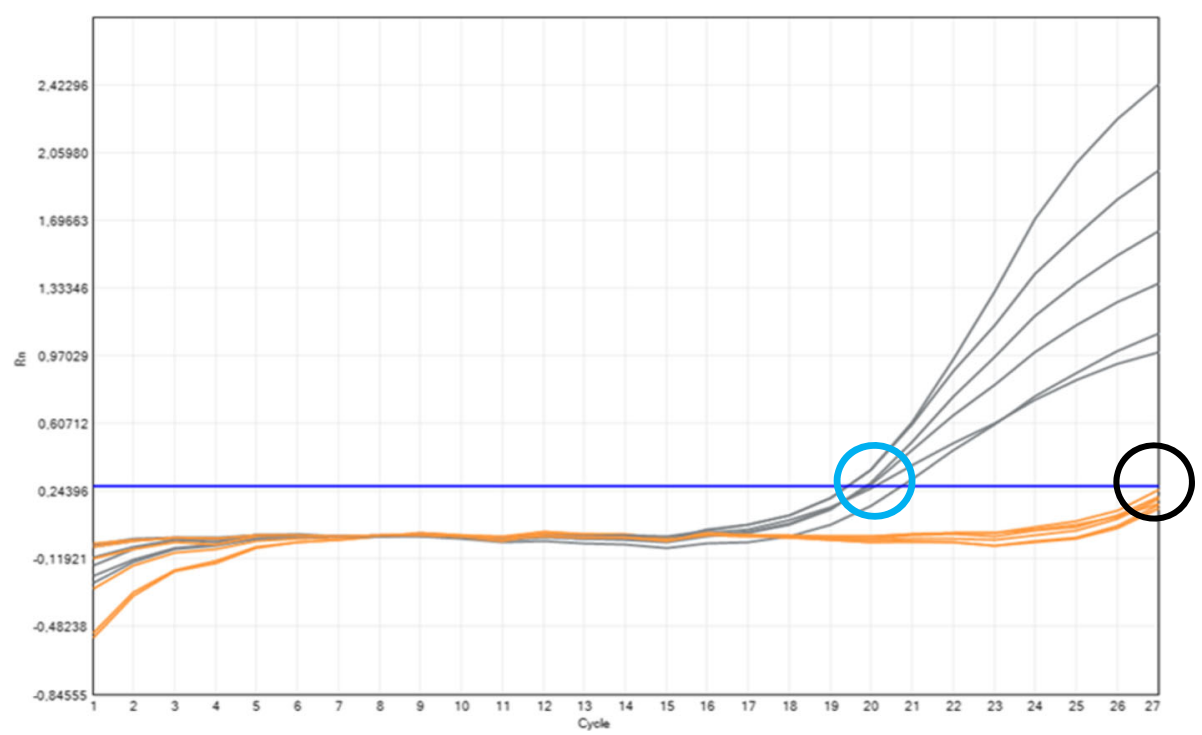

Fig. 3 Behavior of non-carrier samples in the allele specific multiplex-PCR scanning 14 CFTR gene mutations. Wild type (gray) and mutant (orange) curves. The blue circle points out the Ct zone of the wild type PCR, the black circle points out the unspecific amplification of mutant PCR

or discard a sample in a high-throughput scanning of CFTR mutations.

Studies such as this in cystic fibrosis are scarce and very limited, including just a few mutations in the analysis $[16,17]$. Our study highlights the development of a multiplex allele-specific real-time PCR assay for the detection of mutations in the CFTR gene. This offers a significant savings of time and labor compared with the singleplex PCR analysis and provides more qualitative information. Furthermore, the ability to carry out the detection of 13 targets using the same channel is another advantage that reduce the complexity of the necessary equipment. Added to all these benefits the subsequent use of HRMA allows to discriminate the PCR products according to their melting temperature (Tm). The combination of allele-specific PCR and HRMA enables to

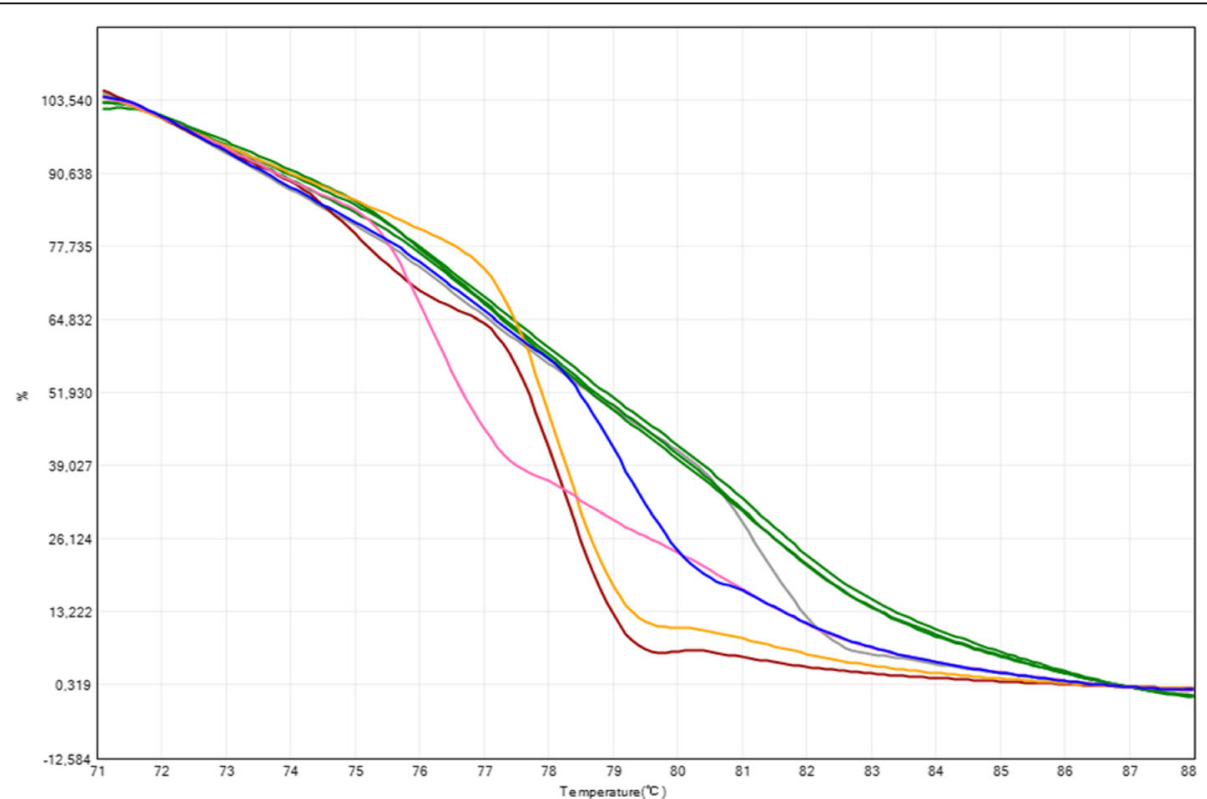

Fig. 4 Determination of the genotype of the sample in the mutant allele specific multiplex PCR. Melting curves obtained at a ramp rate of $0.01{ }^{\circ} \mathrm{C} / \mathrm{s}$. Each color represents a genotype: green (non-carrier), blue (R553X), pink (3120 + 1G > A), brown (F508/N1303K), grey (R334W) and yellow (G542X). HRMA was performed to allow the identification of the mutations when possible 


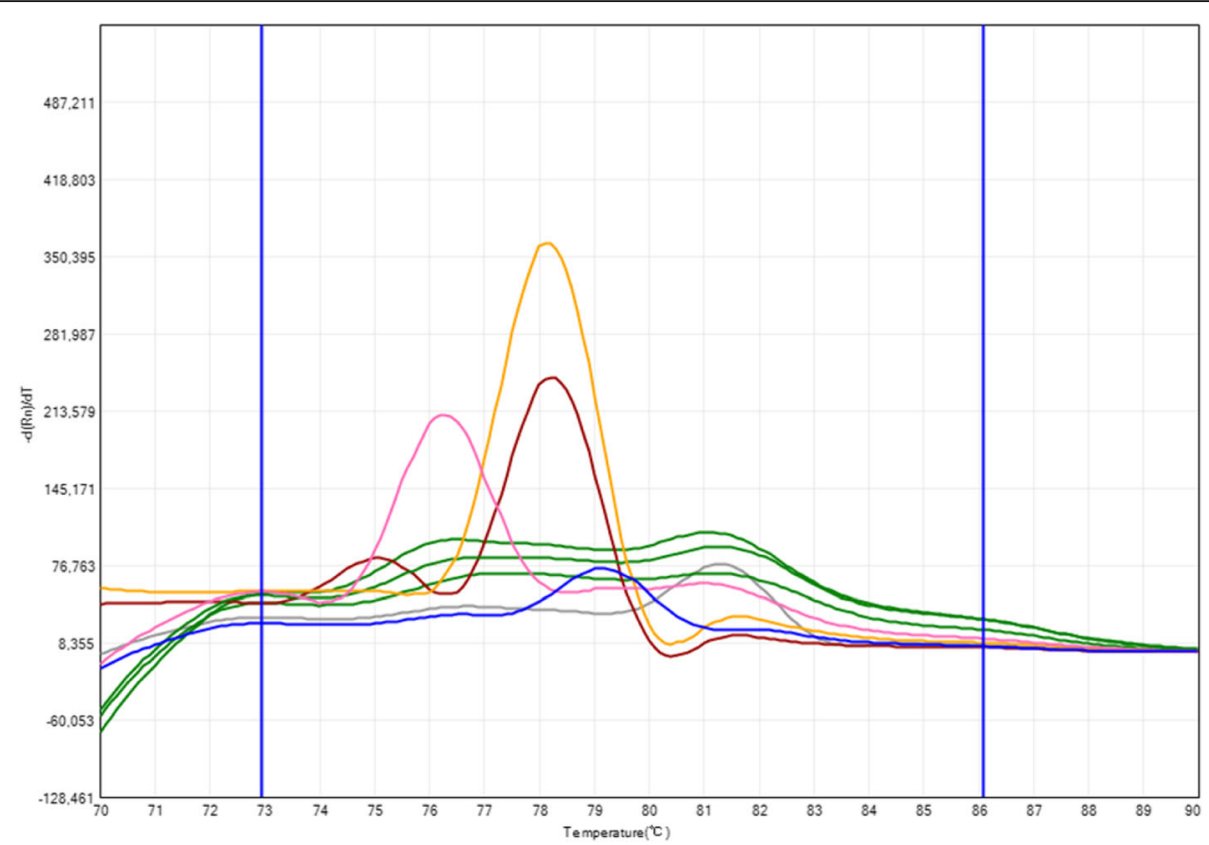

Fig. 5 Derivative melting curve showing the melting peaks of mutant PCR products. The peaks represent the melting temperature of the specific amplified target. HRMA was performed to allow the identification of the mutations when possible

obtain a greater reliability in the results of the samples being analyzed $[18,19]$.

We did not have any sample carrying the genotypes G551D, $1811+1,6 \mathrm{KbA}>\mathrm{G}, 3272-26 \mathrm{~A}>\mathrm{G}$ or W1282X, however, we included those primers in the multiplex PCR due to the high frequency of these mutations in Latin-American countries and their probable presence in the Cuban population. Their inclusion in this scanning technique validates the selectivity of all primers. This strategy could be the most cost-efficiently way to detect these unreported genotypes.

Starting gDNA concentration is a critical factor that could change the interpretation of the PCR curves. All samples tested using this method should have amounts of gDNA over $50 \mathrm{ng}$. Samples below this value will have the $\mathrm{Ct}$ of the wild-type curve two or three cycles later and lower $\Delta \mathrm{Ct}$, producing misleading results. Although the required DNA quantity ( $>50 \mathrm{ng}$ ) is an important parameter to consider for avoiding late amplification, many DNA extraction methods can easily yield this amount.

A Ct value in the mutant PCR indicates the presence of at least one mutation while the $\Delta \mathrm{Ct}$ value indicates the number of affected alleles ( 1 or 2 ). This method simplifies the detection of a carrier sample facilitating the analysis of multiple mutations. The risk of contamination is also reduced because the amplified products never leave the reaction tube.

The HRMA of mutant PCR products confirmed the presence of mutations. The derivative melting curves indicate the melting temperature of the most amplified target in the multiplex PCR. HRMA is a useful technique for scanning exons, but in our study; it was performed to complement the prediction of PCRs, allowing the identification of mutations when possible.

Although current high-throughput sequencing technologies emerge now for screening and detection of somatic mutations, their cost remains high enough to be considered for routinary use in developing countries. Other findings call into question the sensitivity of sequencing methods detecting defined somatic mutations on clinical samples [20, 21]. Taking into account the aforementioned advantages including necessary equipment and reagents availability, we justify and recommend the use of the proposed approach prior to the use of non-specific scanning or sequencing methods in the CF diagnostic algorithm.

\section{Conclusions}

The results published in this work could be the start of a new way to detect CFTR mutations in the Cuban newborn and carrier-screening programs for CF. This approach provides some additional advantages: the cost of mutation screening of the CFTR gene and the time for completing the analysis were reduced. Every sample with suspicion of having mutations could then be reconfirmed and genotyped by using HRMA which increases the reliability of the result. This method could be reproduced in any laboratory with a calibrated real time PCR system. This strategy could also be applicable to any gene, particularly large genes with heterogeneous mutation spectrums. 


\section{Abbreviations}

ARMS: Amplification Refractory Mutation System; CF: Cystic fibrosis; CFTR: Cystic Fibrosis Transmembrane Conductance Regulator; CNGM: National Center of Medical Genetics; Ct: Cycle threshold; DGGE: Denaturing gradient gel electrophoresis; gDNA: Genomic DNA; HRMA: High Resolution Melting Analysis; PCR: Polymerase Chain Reaction; wt: Wild-type

\section{Acknowledgements}

The authors would like to thank Mrs. Laura Quincy Jones who made an important contribution in the correction of the English throughout the manuscript.

\section{Funding}

There was not any source of funding for the realization of this study.

\section{Availability of data and materials}

The datasets used and/or analyzed during the current study are available from the corresponding author on reasonable request.

\section{Authors' contributions}

All authors have made an important contribution to the acquisition, analysis and interpretation of data, the revision of the manuscript content and the approval of the final version to be published.

\section{Competing interests}

All authors declare that they have no financial and non-financial competing interests to report.

\section{Consent for publication}

Not applicable.

\section{Ethics approval and consent to participate}

The Ethic Committee of the National Center for Medical Genetics obtained the written informed consent from all patients or their parents. This Committee approve the selection of participants according to the Internal Regulations for Health Research in the Cuban National Health System [22]. As part as a collaboration between the CNGM and the Immunoassay Center of Havana, this last conducts the analysis of samples only after receiving the approval notices from the Ethics Committee.

\section{Publisher's Note}

Springer Nature remains neutral with regard to jurisdictional claims in published maps and institutional affiliations.

\section{Author details}

'Department of Molecular Biology, Immunoassay Center (CIE) Cubanacan,

Playa, Havana, Cuba. ${ }^{2}$ National Center of Medical Genetics, Havana, Cuba.

Received: 27 December 2016 Accepted: 9 May 2017

Published online: 25 May 2017

\section{References}

1. De Boecka K, Zolinb A, Cuppensc H, Olesend HV, Vivianib L. The relative frequency of CFTR mutation classes in European patients with cystic fibrosis. Cyst Fibros. 2014;13(4):403-9.

2. Dequeker $E$, Stuhrmann M, Morris MA, et al. Best practice guidelines for molecular genetic diagnosis of cystic fibrosis and CFTR-related disordersupdated European recommendations. Eur J Hum Genet. 2009;17(1):51-65.

3. Pérez MM, Luna MC, Pivetta OH, Keyeux G. CFTR gene analysis in Latin American CF patients: Heterogeneous originand distribution of mutations across the continent. J Cyst Fibros. 2007:6:194-208.

4. Keyeux G, Rodas C, Bienvenu T, Garavito P, Vidaud D, Sanchez D. CFTR mutations in patients from Colombia: Implications for local and regional molecular diagnosis programs. Hum Mutat. 2003:22:259.

5. González JA, Abreu G, Rodríguez F. Reseña histórica de la fibrosis quística y su estudio y tratamiento en Cuba. Rev Cubana Pediatr. 2014;86(4):535-40.

6. Castellani $\mathrm{C}$, Cuppens $\mathrm{H}$, Macek M, et al. Consensus on the use and interpretation of cystic fibrosis mutation analysis in clinical practice. J Cyst Fibros. 2008;7(3):179-96.
7. Audrezet MP, Dabricot A, Le Marechal C, Ferec C. Validation of HighResolution DNA Melting Analysis for Mutation Scanning of the Cystic Fibrosis Transmembrane Conductance Regulator (CFTR) Gene. J Mol Diagn. 2008:10(5):424-34

8. Montgomery J, Wittwer CT, Kent JO, Zhou L. Scanning the cystic fibrosis transmembrane conductance regulator gene using high resolution DNA melting analysis. Clin Chem. 2007;53(11):1891-8.

9. Richards CS, Bradley LA, Amos J, Allitto B, Grody WW, Maddalena A, et al. Standards and quidelines for CFTR mutation testing. Genet Med. 2002;4(5):379-91.

10. Figueredo JE, Armas A, González YJ, Collazo T, García I, Perea Y, Santos EN. Development of a method to detect three frequent mutations in the CFTR gene using allele-specific real time PCR. Biotec Apl. 2015;32:4301-6.

11. Soloviov OO, Pampukha VM, Livshits LA. Development of ARMS PCR tests for detection of common CFTR gene mutations. Biopolym Cell. 2010;26(5):378-83.

12. Krenkova P, Norambuena P, Stambergova A, Macek Jr M. Evaluation of High-Resolution Melting (HRM) for Mutation Scanning of Selected Exons of the CFTR Gene. Folia Biol. 2009:55:238-42.

13. Schrijver I, Ramalingam S, Sankaran R, Swanson S, Dunlop CLM, Keiles S, Moss RB, Oehlert J, Phyllis Gardner E. Robert Wassman, Anja Kammesheidt, Diagnostic Testing by CFTR Gene Mutation Analysis in a Large Group of Hispanics. J Mol Diagn. 2005;7(2):289-99.

14. Perone C, Medeiros GS, del Castillo DM, de Aguiar MJB, Januário JN. Frequency of 8 CFTR gene mutations in cystic fibrosis patients in Minas Gerais, Brazil, diagnosed by neonatal screening. Braz J Med Biol Res. 2010;43(2):134-8.

15. Ramirez AM, Ramos MD, Jimenez J, Ghio A, de Botelli MM, Rezzonico CA, et al. Mutational spectrum of cystic fibrosis patients from Cordoba province and its zone of influence: implications of molecular diagnosis in Argentina. Mol Genet Metab. 2006;87(4):370-5.

16. Dempsey E, Barton DE, Ryan F. Detection of five common CFTR mutations by Rapid-Cycle Real-Time Amplification refractory mutation system PCR. Clin Chem. 2004:50(4):773-5.

17. Chen N, Prada AE. Development of allele-specific multiplex PCR to determine the length of poly-T in intron 8 of CFTR. PeerJ. 2014:2:e468. doi: 10.7717/peerj.468

18. Ramezanzadeh M, Mansour S, Rasoul S. Assessment of high resolution melt analysis feasibility for evaluation of beta-globin gene mutations as a reproducible, cost-efficient and fast alternative to the present conventional method. Adv Biomed Res. 2016;5:71.

19. Ryan SE, Ryan F, O'Dwyer $V$, Neylan D. A real-time ARMS PCR/highresolution melt curve assay for the detection of the three primary mitochondrial mutations in Leber's hereditary optic neuropathy. Mol Vis. 2016;22:1169-75.

20. Ellison G, Donald E, McWalter G, Knight L, Fletcher L, Sherwood J, et al. A comparison of ARMS and DNA sequencing for mutation analysis in clinical biopsy samples. J Exp Clin Cancer Res. 2010;29:132

21. Shaozhang Z, Ming Z, Haiyan P, Aiping Z, Qitao Y, Xiangqun S. Comparison of ARMS and direct sequencing for detection of EGFR mutation and prediction of EGFR-TKI efficacy between surgery and biopsy tumor tissues in NSCLC patients. Med Oncol. 2014;31(5):1-9.

22. Echemendía TB, Suárez M, Suárez R, Cuéllar L, Gutiérrez T. Reglamento interno del Comité de Ética de la Investigación en Salud, un instrumento para el mejoramiento del desempeño. Rev Cubana Hig Epidemiol. 2013;51(3):355-64.

\section{Submit your next manuscript to BioMed Central and we will help you at every step:}

- We accept pre-submission inquiries

- Our selector tool helps you to find the most relevant journal

- We provide round the clock customer support

- Convenient online submission

- Thorough peer review

- Inclusion in PubMed and all major indexing services

- Maximum visibility for your research

Submit your manuscript at www.biomedcentral.com/submit
BioMed Central 